\title{
Effectiveness of architectural separation of septic and aseptic operating theatres for improving process quality and patient outcomes: a systematic review
}

\author{
Romy Scholz ${ }^{1}$, Alexander Hönning ${ }^{1 *}$, Julia Seifert ${ }^{2}$, Nikolai Spranger ${ }^{2}$ and Dirk Stengel ${ }^{1,2,3}$
}

\begin{abstract}
Background: Architectural division of aseptic and septic operating theatres is a distinct structural feature of surgical departments in Germany. Internationally, hygienists and microbiologists mainly recommend functional separation (i.e. aseptic procedures first) without calling for separate operating floors and rooms. However, patients with severe musculoskeletal infections (e.g. joint empyema, spondylodiscitis, deep implant-associated infections) may benefit from the permanent availability of septic operating capacities without delay caused by an ongoing aseptic surgical program. A systematic literature review on the influence of a structural separation of septic and aseptic operating theatres on process and/or outcome quality has not yet been conducted.
\end{abstract}

Methods: Systematic literature search in PubMed MEDLINE, Ovid Embase, CINAHL and the Cochrane Library, screening of referenced citations, and assessment of grey literature.

Results: A total of 572 articles were found through the systematic literature search. No head-to-head studies (neither randomised, quasi-randomised nor observational) were identified which examined the impact of structural separation of septic and aseptic operating theatres on process and/or outcome quality.

Conclusions: This review did not identify evidence in favour nor against architectural separation of septic or aseptic operating theatre. Specifically, there is no evidence of a harmful effect of architectural separation. Unless prospective studies, ideally randomised trials, will be available, it is unjustified to call for abolishing established hospital structures. Future investigations must address patient-centered endpoints, surgical site infections, process quality and hospital economy.

Systematic review registration: PROSPERO (International prospective register of systematic reviews): CRD42018086568.

Keywords: Aseptic, Septic, Spatial separation, Operating room, Surgical site infection, Process quality

\section{Background}

Architectural separation of aseptic and septic operating theatres is a traditional structural feature of many hospitals in Germany which may be less frequently found in other European countries and surgical departments around the globe.

The philosophy of dedicated, spatially separated septic operating theatres has been questioned by hospital

\footnotetext{
* Correspondence: alexander.hoenning@ukb.de

'Centre for Clinical Research, BG Hospital Unfallkrankenhaus Berlin, Berlin, Germany Full list of author information is available at the end of the article
}

hygienists and microbiologists. They argue the concept is outdated and inefficient, and that clean and contaminated operations may safely be carried out in the same suite given proper functional separation (i.e. ordering schedules from aseptic to septic procedures) and sufficient wipe disinfection.

In 2017, an exploratory analysis of 16 septic and 14 aseptic general surgical procedures performed in a single theatre without laminar air flow showed no differences in bacterial air contamination and sedimentation [1]. Based on the results, an accompanying editorial concluded that 
"separation of septic and aseptic surgical areas is obsolete" [2]. This interpretation is unjustified, as the study was not designed to compare different theatre environments in a head-to-head fashion.

Protagonists of structural separation stress its logistic advantages and potential benefits for patients with severe infections. Permanent availability of a septic theatre and surgical team may guarantee that often complex debridement and revision procedures are performed during regular working hours. Otherwise, according to the principle of functional separation, rather sick patients can only be operated on after the aseptic surgical program has been accomplished. Emergency cases demanding immediate intervention may further interrupt schedules and postpone planned septic surgeries.

Determining and improving process quality and patient outcomes in operating theatres emerged as an area of active research across the globe [3-29]. However, the influence of the architectural division of aseptic and septic operating theatres on process quality and patient outcomes remains unclear.

We conducted a systematic review addressing the question whether structural separation of septic and aseptic operating theatres compared to alternative room and floor architecture is associated with improved process and/or outcome quality.

\section{Methods}

\section{Selection criteria and search strategy}

This systematic review complied with PRISMA guidelines (see Additional file 1 for a completed checklist). The literature search was performed on March 9, 2018. We searched the following electronic bibliographic databases with no language or publication status limitations since January 1968: PubMed MEDLINE, Ovid Embase, CINAHL and the Cochrane Library. The PubMed MEDLINE search strategy can be found in Table 1. Publications were identified using a prospectively defined algorithm and pre-defined selection criteria. Additional literature (including grey literature) was identified by a snowball search (e.g. "related articles" in PubMed, reference lists of identified publications) and by an internet search on the websites of relevant institutions.

For the qualitative part of the systematic review, original papers and any other identified literature were considered. For the quantitative part, data from all types of comparative studies were potentially eligible for synthesis (i.e. randomised controlled trials [RCT], quasi-RCT and cohort studies), provided that a sufficient number of studies of adequate quality were available.

\section{Primary outcome}

Influence of spatial separation of septic and aseptic operating rooms as a feature of structural quality on:
Table 1 PubMed MEDLINE search strategy (limited to publication date range 01.01.1968-present)

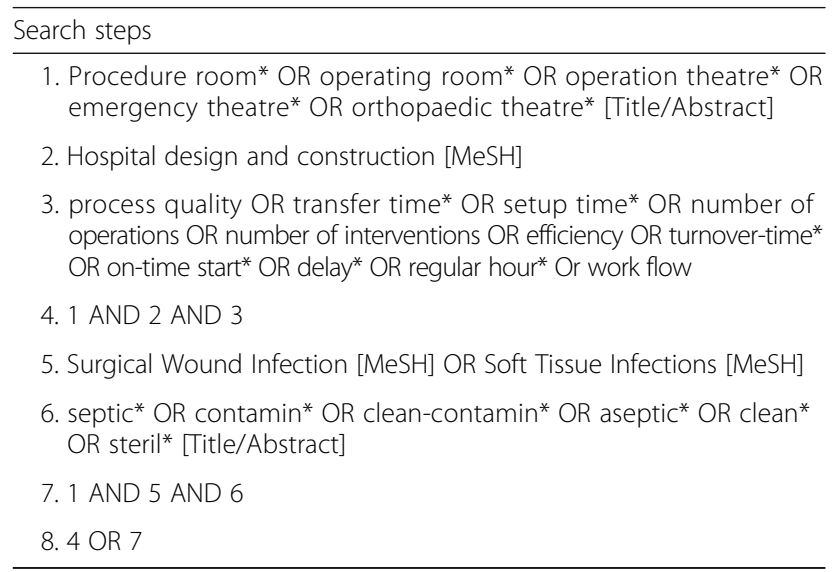

\section{- Process quality}

- Shortening of transfer and setup times

- Number of septic interventions performed during regular daily operating work hours, according to previous planning and schedules (e.g., 07:00 A.M. to 05:00 P.M.) and

\section{- Outcome quality}

- Incidence of nosocomial infections (especially wound and soft tissue infections)

- Prevalence of multidrug-resistant pathogens such as methicillin-resistant Staphylococcus aureus spec. (MRSA), extended-spectrum beta-lactamase (ESBL)producing bacteria, multidrug-resistant gram-negative bacteria (3/4 MRGN)

- Rate of healing in musculoskeletal and implant-associated infections

- Incidence of surgical and non-surgical complications

- Generic and disease-specific patient-centered outcomes

\section{Data extraction (selection and coding)}

Records identified were exported to bibliographic software (EndNote V7.7, Thomson Reuters). Duplicate records were reviewed and excluded when necessary. Titles and abstracts of all identified articles were screened for eligibility against the review selection criteria. Screening of articles, data extraction and critical appraisal were independently undertaken by two reviewers, with a third reviewer consulted in case of disagreement. A list of potentially relevant studies read in full-text form but excluded from the review was provided, justifying exclusion of the particular citation from the review.

\section{Risk of bias (quality) assessment}

The bias potential of included studies was evaluated using the ROBINS-I tool [30], which was developed for 
the assessment of quantitative non-randomised studies in systematic reviews. For this purpose, the risk of biaslow, moderate, severe or critical-was assessed by seven domains (confounding, selection of participants in the study, classification of interventions, deviations from intended interventions, missing data, measurement of results or interventions, selection of reported results) and then summarised for each study. Studies that were assessed in the overall assessment with a critical bias potential according to ROBINS-I were not used to answer the research question, as their results were considered to be too biased to contribute meaningful evidence.

\section{Strategy for data synthesis}

Depending on the number of studies and the degree of heterogeneity, the best available evidence can be aggregated using a meta-analysis or narrative synthesis. In case of a sufficient number of studies, homogeneous data and a noncritical potential for bias, it was planned to apply a random-effects meta-analysis, taking into account variations in effect sizes between interventions and typically expanding confidence intervals in case of heterogeneity. We also considered a sensitivity analysis including only studies with low or medium risk of bias to test the robustness of primary results.

\section{Results}

In the qualitative part of the review, a total of 572 articles were found through the systematic literature search in PubMed MEDLINE, Ovid Embase, CINAHL and the Cochrane Library, as well as through the identification of additional literature (Fig. 1).

Of these, 310 were on PubMed MEDLINE, 138 on Ovid Embase, 62 on CINAHL and 48 on the Cochrane Library. Fifteen articles were additionally identified through other sources. After the removal of duplicates, 401 articles remained, which were examined for suitability with regard to the selection criteria by title and abstract. Further, 373 articles were excluded because they could not be used to answer the research question. The remaining 28 articles were analysed in full text. Of these articles, 27 were excluded due to a lack of separation of septic or aseptic operating theatres or the articles did not contain evaluable data (correspondence, editorial).

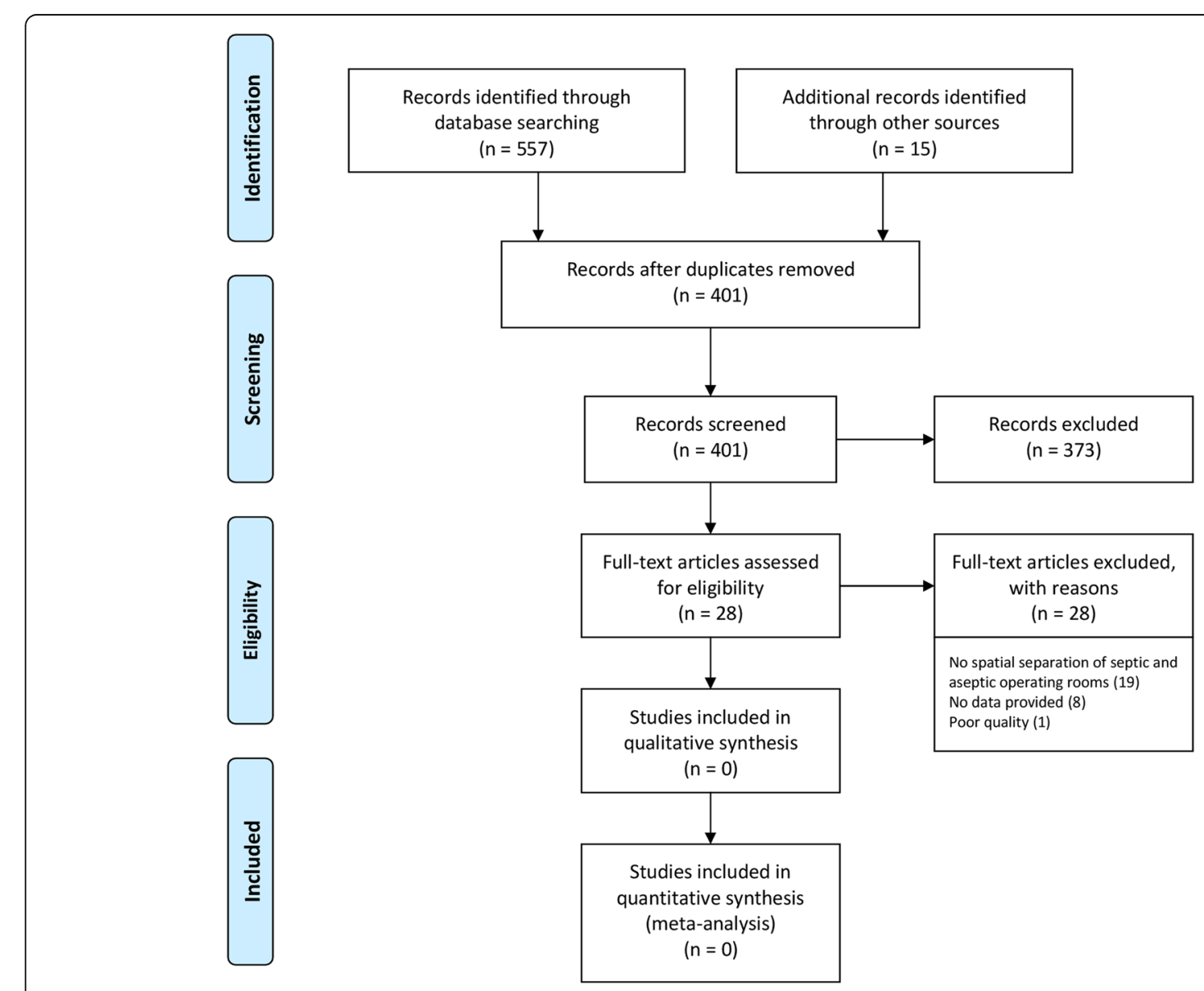

Fig. 1 PRISMA flow chart 
Table 2 Study characteristics of Daschner et al.

\begin{tabular}{|c|c|c|}
\hline & Septic operating theatre & Aseptic operating theatre \\
\hline Objectives & \multicolumn{2}{|c|}{$\begin{array}{l}\text { To study the microbiology of air and floor samples obtained in an aseptic and septic operating theatre prior to (morning) and } \\
\text { after completion of the daily surgical program (evening). }\end{array}$} \\
\hline Sampling method & \multicolumn{2}{|c|}{$\begin{array}{l}\text { One day per week during } 5 \text { months, before first surgery and after last surgery. } \\
\text { Floor: RODAC blood agar plates at nine different points around the operating table. } \\
\text { Air: Approximately middle of the room ( } 25 \mathrm{~cm} \text { higher than operating table) using a "Reuter-Centrifugal-Sampler" with a suction } \\
\text { volume of } 80.94 \text { I in } 2 \text { min. }\end{array}$} \\
\hline Setting & $\begin{array}{l}\text { Operating room, floor, gowning area for personnel only, washing room accessible } \\
\text { through operating room only, all rooms except one for septic unit access were not } \\
\text { closable/lockable, window ventilation }\end{array}$ & $\begin{array}{l}\text { Clean air system, gowning area for patients } \\
\text { and personnel }\end{array}$ \\
\hline Disinfection method & $\begin{array}{l}\text { Unit floor: } 0.5 \% \text { aldehyde disinfectant every day before first surgery and after last } \\
\text { surgery, operating room floor after every single surgery }\end{array}$ & $\begin{array}{l}\text { Unit floor: } 0.5 \% \text { aldehyde disinfectant every } \\
\text { day after last surgery, operating room floor } \\
\text { after every single surgery }\end{array}$ \\
\hline No. of procedures & 183 & 130 \\
\hline \multicolumn{3}{|c|}{ Air samples, mean CFU/m³ (SD) } \\
\hline Morning & $798.4(552.4)$ & $774.0(826.2)$ \\
\hline Evening & $424.8(301.1)$ & $565.2(521.0)$ \\
\hline \multicolumn{3}{|c|}{ Plate samples, mean CFU/16 cm² } \\
\hline Theatre, morning & 9.3 & 6.4 \\
\hline Theatre, evening & 31.5 & 8.4 \\
\hline Corridor, morning & 18.8 & 12.8 \\
\hline Corridor, evening & 14.8 & 18.3 \\
\hline $\begin{array}{l}\text { Gowning area, } \\
\text { morning }\end{array}$ & 32.7 & 28.5 \\
\hline $\begin{array}{l}\text { Gowning area, } \\
\text { evening }\end{array}$ & 53.4 & 56.1 \\
\hline SSI rate after 8 weeks & $10.9 \%$ & $3.0 \%$ \\
\hline
\end{tabular}

Accordingly, only one investigation published more than 30 years ago remained which provided some information on the review question (Daschner et al. [31]).

Subject of the study by Daschner et al. was a qualitative and quantitative comparison of the bacterial spectrum of the air and floor of an aseptic and a septic surgery unit (Table 2).

They stated that there was no significant difference in airborne bacteria and that floor contamination showed only little difference.

Wound infection rate was $10.9 \%$ for septic surgeries and 3\% for aseptic surgeries. The responsible bacteria could not be isolated from the air or floor of the corresponding operating theatre. They suggest zoning of operating rooms rather than an architectural separation.

However, the publication had a critical risk of bias due to uncontrolled confounding (e.g. outdated disinfection measures, air conditioning of septic operating room by window ventilation). Thus, the study does not provide meaningful evidence to answer the research question.

\section{Discussion}

The aim of the systematic literature analysis was to answer the question whether the structural separation of septic and aseptic operating rooms affects indicators of process and outcome quality. There are currently no head-to-head comparisons of structurally divided surgical floors with alternative approaches like functional separation of aseptic and septic procedures. The available indirect information is insufficient to draw meaningful conclusions on this problem either.

\section{Conclusions}

Absence of evidence does not constitute evidence of absence. From a scientific point of view, it is currently unjustified to conclude that architectural separation is useless. The lack of convincing data in favour of this distinct structural feature should prompt prospective trials to study the impact of spatial segregation of septic and aseptic operating theatres on patient-centered endpoints (especially with regard to postoperative wound infections and soft tissue infections) and process quality.

\section{Additional file}

Additional file 1: PRISMA 2009 Checklist. (DOC 62 kb) 


\section{Abbreviations}

CINAHL: Cumulative index to nursing and allied health literature; Embase: Excerpta medica database; MEDLINE: Medical literature analysis and retrieval system online; PRISMA: Preferred reporting items for systematic reviews and meta-analyses; ROBINS-I: A Cochrane risk of bias assessment tool: for non-randomised studies of interventions; SAV: Severe injury type procedure; VAV: Injury type procedure

\section{Acknowledgements}

Not applicable.

\section{Funding}

This research was supported by the German Social Accident Insurance (DGUV) (Deutsche Gesetzliche Unfallversicherung, DGUV), Vorhabenskennzeichen FR291. The authors are responsible for the content of this publication.

\section{Availability of data and materials}

Not applicable.

\section{Authors' contributions}

RS and AH designed and conducted the literature search and screened the studies. RS drafted the manuscript. AH, DS, JS and NS revised the manuscript for important intellectual content. DS planned the review, obtained funding and supervised the study. All authors read and approved the final manuscript.

\section{Ethics approval and consent to participate}

Not applicable.

\section{Consent for publication}

Not applicable.

\section{Competing interests}

The research institution, i.e., the BG hospital Unfallkrankenhaus Berlin, is affiliated with the Hospital Group of the Statutory Accident Insurance. The German Social Accident Insurance is the sponsor of this review. The sponsor has no influence on study design, data analysis and reporting.

\section{Publisher's Note}

Springer Nature remains neutral with regard to jurisdictional claims in published maps and institutional affiliations.

\section{Author details}

${ }^{1}$ Centre for Clinical Research, BG Hospital Unfallkrankenhaus Berlin, Berlin, Germany. ' Department of Trauma and Orthopaedic Surgery, BG Hospital Unfallkrankenhaus Berlin, Berlin, Germany. ${ }^{3}$ Hospital Group of the Statutory Accident Insurance, Berlin, Germany.

Received: 30 August 2018 Accepted: 26 December 2018

Published online: 09 January 2019

\section{References}

1. Harnoss JC, Assadian O, Diener MK, Muller T, Baguhl R, Dettenkofer M, et al. Microbial load in septic and aseptic procedure rooms. Dtsch Arztebl Int. 2017;114(27-28):465-75.

2. Bischoff $P$, Gastmeier $P$. The separation of septic and aseptic surgical areas is obsolete. Dtsch Arztebl Int. 2017;114(27-28):463-4.

3. Waeschle RM, Sliwa B, Jipp M, Putz H, Hinz J, Bauer M. Performance development of a university operating room after implementation of a central operating room management. Anaesthesist. 2016;65(8):615-28.

4. Attarian DE, Wahl JE, Wellman SS, Bolognesi MP. Developing a highefficiency operating room for total joint arthroplasty in an academic setting. Clin Orthop Relat Res. 2013:471(6):1832-6.

5. Weiss $G$, von Baer R, Riedl S. Influence of the space layout of a surgical department on use efficiency. Chirurg. 2002:73(2):174-9.

6. Hawkins HR, Gover RE. The design of today's operating rooms. Todays Surg Nurse. 1998;20(1):11-5. quiz 45-6

7. Birgand G, Saliou P, Lucet JC. Influence of staff behavior on infectious risk in operating rooms: what is the evidence? Infect Control Hosp Epidemiol. 2015;36(1):93-106.

8. Attri JP, Khetarpal R, Chatrath V, Kaur J. Concerns about usage of smartphones in operating room and critical care scenario. Saudi J Anaesth. 2016;10(1):87-94.
9. Blood AG, Sandoval MF, Burger E, Halverson-Carpenter K. Risk and protective factors associated with surgical infections among spine patients. Surg Infect. 2017;18(3):234-49.

10. Chauveaux D. Preventing surgical-site infections: measures other than antibiotics. Orthop Traumatol Surg Res. 2015;101(1 Suppl):S77-83.

11. Cristina ML, Sartini M, Schinca E, Ottria G, Spagnolo AM. Operating room environment and surgical site infections in arthroplasty procedures. J Prev Med Hyg. 2016;57(3):E142-E8.

12. Dellinger EP. Teamwork and collaboration for prevention of surgical site infections. Surg Infect. 2016;17(2):198-202.

13. Graves N, Wloch C, Wilson J, Barnett A, Sutton A, Cooper N, et al. A costeffectiveness modelling study of strategies to reduce risk of infection following primary hip replacement based on a systematic review. Health Technol Assess. 2016;20(54):1-144.

14. Kucukdurmaz F, Parvizi J. The prevention of periprosthetic joint infections. Open Orthop J. 2016;10:589-99.

15. Loftus RW. Infection control in the operating room: is it more than a clean dish? Curr Opin Anaesthesiol. 2016;29(2):192-7.

16. Markatos K, Kaseta M, Nikolaou VS. Perioperative skin preparation and draping in modern Total joint arthroplasty: current evidence. Surg Infect. 2015;16(3):221-5.

17. Olmsted RN. Prevention by design: construction and renovation of health care facilities for patient safety and infection prevention. Infect Dis Clin N Am. 2016;30(3):713-28.

18. O'Neal JB, Shaw AD. Goal-directed therapy in the operating room: is there any benefit? Curr Opin Anaesthesiol. 2016:29(1):80-4.

19. Pada S, Perl TM. Operating room myths: what is the evidence for common practices. Curr Opin Infect Dis. 2015;28(4):369-74.

20. Prabhakar A, Wyche MQ, 3rd, Ehrhardt KP, Jr., Ma JG, Elhassan AO, Urman $\mathrm{RD}$, et al. Novel improvements in perioperative sterility. J Med Pract Manage. 2015;30(6 Spec No):48-50.

21. Dumville JC, McFarlane E, Edwards P, Lipp A, Holmes A, Liu Z. Preoperative skin antiseptics for preventing surgical wound infections after clean surgery. Cochrane Database Syst Rev. 2015;4:CD003949.

22. Reichel M, Heisig P, Kohlmann T, Kampf G. Alcohols for skin antisepsis at clinically relevant skin sites. Antimicrob Agents Chemother. 2009;53(11): 4778-82.

23. Tanner J, Woodings D, Moncaster K. Preoperative hair removal to reduce surgical site infection. Cochrane Database Syst Rev. 2006;3:CD004122.

24. Harnoss JC, Partecke LI, Heidecke CD, Hubner NO, Kramer A, Assadian O. Concentration of bacteria passing through puncture holes in surgical gloves. Am J Infect Control. 2010;38(2):154-8.

25. Lehtinen SJ, Onicescu G, Kuhn KM, Cole DJ, Esnaola NF. Normothermia to prevent surgical site infections after gastrointestinal surgery: holy grail or false idol? Ann Surg. 2010;252(4):696-704.

26. Anderson DJ, Podgorny K, Berrios-Torres SI, Bratzler DW, Dellinger EP, Greene $L$, et al. Strategies to prevent surgical site infections in acute care hospitals: 2014 update. Infect Control Hosp Epidemiol. 2014;35(Suppl 2): S66-88.

27. Young SW, Zhu M, Shirley OC, Wu Q, Spangehl MJ. Do 'Surgical helmet Systems' or 'Body exhaust Suits' affect contamination and deep infection rates in arthroplasty? A systematic review. J Arthroplast. 2016;31(1):225-33.

28. Tanner J, Dumville JC, Norman G, Fortnam M. Surgical hand antisepsis to reduce surgical site infection. Cochrane Database Syst Rev. 2016;1: CD004288.

29. Kao LS, Meeks D, Moyer VA, Lally KP. Peri-operative glycaemic control regimens for preventing surgical site infections in adults. Cochrane Database Syst Rev. 2009;3:CD006806.

30. Sterne JA, Hernan MA, Reeves BC, Savovic J, Berkman ND, Viswanathan M, et al. ROBINS-I: a tool for assessing risk of bias in non-randomised studies of interventions. BMJ. 2016:355:14919.

31. Daschner FBM, Bönig G, Langmaack H, Brobmann G. Luft- und Bodenkeimspektren in einer septischen und aseptischen Operationseinheit. Akt Chir. 1984;19:17-20. 